\title{
The Development of High-Quality Course Construction in Chinese University Based on MOOC
}

\author{
Haiyan WANG ${ }^{1}$, Yanming $\mathrm{ZHAO}^{2}$ \\ ${ }^{1}$ Faculty of Mining and Safety Engineering China University of Mining \& Technology (Beijing), Beijing, PRC \\ ${ }^{2}$ Department of Mathematics and Computer Hebei Normal University for Nationalities, Chengde, Hebei Province, PRC \\ \{whyhyp\}@163.com, zhaoyanming007@163.com
}

\begin{abstract}
Massive Open Online Course (MOOC) is changing learners' learning means and learning environment with a new knowledge acquisition method and learning pattern. Aiming at improving sharing of superior educational resources and relieving education unfairness, high-quality course construction in universities has been chosen as the key subject of educational reform by Ministry of Education of P.R.C. Under the high-tech educational background represented by MOOC, research on opportunities, challenges and countermeasures of high-quality courses have become a hot topic of the current researches. Thus, this paper analyzed the theoretical and philosophical foundation of High-Quality Course Construction and put forward MOOC could be effectively combined with High-Quality Course Construction under the theoretical support of sticking to sustainable development. Finally, the development strategy of High-Quality Course Construction under MOOC was proposed.
\end{abstract}

Index Terms - MOOC, network course, high-quality course, course construction, sustainable development

\section{Introduction}

Massive Open Online Course [1] (MOOC) is characterized by large scale, strong openness, student orientation and lower learning cost, and it has become a key subject of current network learning and internet research. As an on-line learning means, MOOC has formed certain commercial size, and under the jointly participation of enterprises and famous universities in west developed countries. MOOC is gradually changing learning's means of acquiring knowledge. In China, MOOC has also attracted the attention and thoughts of researchers of higher education as well as the higher education management institutions [2]-[8]. High-Quality Course Construction in universities is the key research subject of Ministry of Education of PRC. How to survive and develop is need to be solved for high-quality courses under the background of MOOC. Its solution is significant to enlightenment to the course reform of Chinese universities and is great importance to sustainable development of high-quality courses as well as the sharing of superior educational resources. And then, it will promote the educational fairness. Based on this, the paper puts forward the opportunities and countermeasures of HighQuality Course Construction in universities under the hightech environment and demonstrates it with the example of MOOC. The philosophical basic of High-Quality Course Construction and development, namely sustainable development, was analyzed firstly. Moreover, the opportunities, challenges and countermeasures of High-
Quality Course Construction under the background of advanced technology were expounded by combining HighQuality Course Construction with MOOC background effectively.

\section{Definition and Philosophical Basis of High-Quality Courses in Universities}

High-quality courses[5] construction is an important subject on the sustainable development of high-quality education raised in Outline of National Medium-and LongTerm Program for Education Reform and Development (20112020) (hereinafter referred to as " PERD"), which is an important method to realize higher education fairness and improve higher education quality as well as an important constituent part of teaching quality and reform program of colleges and universities. According to PERD, it can be analyzed that high-quality courses have the following characteristics.

(1) The characteristic of "five tops", and that is, top teaching body, top teaching content, top teaching materials, top teaching methods and top teaching management [9]. This characteristic is an important guiding thought and evaluation index of high-quality courses, which is of good operability and can furthest eradicate the election of low-quality courses.

(2) The characteristic of sustainable development. It is the soul of high-quality courses and the philosophical basis for the existence, development and sustainability of high-quality courses, as well as the innovation of national sustainable development in the field of education. This characteristic explains the sustainability of high-quality course from two aspects. On the one hand, it explains the sustainable development of high-quality courses in content construction and standard restrictions; on the other hand, it shows that high-quality courses can refer to or rely on other advanced technological means and farthest realize educational fairness without increasing the educational input in all directions.

(3) The characteristic of promoting educational fairness and improving teaching means, which is also the ultimate goal of High-Quality Course Construction. High-Quality Course Construction involves huge investment, whose main purpose is to eliminate the regional difference of education and teaching resources, realize the sharing of superior educational resources, promote educational fairness and improve education and teaching quality. 
Among the above characteristics, sustainable development is the soul of high-quality course, the internal motivation of high-quality courses development as well as the philosophical basis and theoretical innovation for the existence of highquality courses. Before the release of the PERD, there were already relevant projects related to High-Quality Course Construction inside Chinese universities, but they were not formally put forward yet. Most of them were concerned with the course construction inside the department or the connection between old and new course system construction. Such courses preliminarily reflected the four basic characteristics of High-Quality Course Construction, but their construction input was relatively less, the influential scope was restricted and they couldn't well integrate the new technological development. Since the release of PERD, there has been explicit purpose, strict restriction and government support on High-Quality Course Construction, and some enterprises have been involved in High-Quality Course Construction as well, which brings High-Quality Course Construction new vitality as well as more challenges. Such content has fully reflected the sustainable development of High-Quality Course Construction. The sustainable development of high-quality courses determines the sustainability of the development content and method of highquality courses under the background of new technology (such as MOOC), and fully reflects the purpose of centring on education. And then, the teaching difference in universities would be eliminated gradually and teaching quality would be improved finally.

The sustainable development of high-quality courses can be classified into two aspects. Firstly, it is the sustainable development of course content. With the continuous progress of science and technology and the development of subject knowledge, the subject content of High-Quality Course Construction needs constant enrichment in order to reflect the advancement of subjects fully. With the change of personnel structure and the joint of new researchers, the subject depth and width of high-quality courses are increased, further promoting the sustainable development of course content. Secondly, the emergence of modern educational technological methods and new communication means has provided new opportunities and challenges for the spreading, communication and sharing of high-quality courses. Opportunities mean under the background of new technology, based on sustainable development, high-quality courses have to take in the fresh air continuously, constantly taking in the advantages of new technology to improve their development ability. Challenges mean high-quality courses will receive impacts from technology, learning and mode of transmission under the background of new technology. To handle these impacts well, high-quality courses must stick to the soul and essence, namely sustainable development, so as to deal with various challenges effectively.

Under the concern of Ministry of Education of PRC and relevant national departments, the high-quality courses constructed in Chinese universities has realized about 20,000[10], among which the distribution is balanced and of high quality in general. It fully shows that Chinese HighQuality Course Construction has achieved relatively good phased objectives, which has provided an important guarantee for the High-Quality Course Construction under the background of high technology.

\section{Comparative Analysis of the Sustainable Development State of High-Quality Courses in Chinese Universities}

From the perspective of technology, the development of High-Quality Course Construction can be generally divided into three modes, namely High-Quality Course Construction under the traditional educational pattern, High-Quality Course Construction under the network teaching platform and HighQuality Course Construction under the MOOC network education platform which is just beginning in China. Under the circumstance of developing in succession and influencing mutually, they are continuously promoting the development of High-Quality Course Construction, in which process the latter one solves the defects of the former one and generates new defects at the same time.

A. Development of High-Quality Course Construction under the Traditional Educational Pattern

The paper defines the High-Quality Course Construction before the release of PERD as "limited High-Quality Course Construction", and here "limited" mainly means: (1) limited technological background, which just relies on traditional audio-visual education method; (2) limited influence scope, which is just restricted to the internal disciplinary communication at a time in a certain place, focusing on paper documents supplemented by electronic literature; (3) limited propaganda distance, which is only restricted to the internal subject of the school whose subject category is limited with lower coverage scope. Though "limited" High-Quality Course Construction had an important driving effect on educational reform and progress at that time, it still needs new technological means to break its "limitation" and promote the altitude of High-Quality Course Construction, which will further give full play to the sustainable development of the content of High-Quality Course Construction under the background of sustainable technological development.

\section{B. Development of High-Quality Course Construction Under The Network Environment}

With the development of network technology together with internet business, a brand new resource communication and sharing mechanism—network teaching platform rises at the right moment. This platform realizes the basic process of teaching and learning under the network environment, which realizes sharing of superior teaching resources and can solve the regional difference of high-quality teaching resources in universities. As a result, High-Quality Course Construction is experiencing new opportunities and challenges. Around the world, the study and application of network teaching platform 
develops rapidly. Under such a technological background, department in charge of education released PERD, in which it explicitly defined many elements and key characteristics of High-Quality Course Construction. Under the background of network technology, High-Quality Course Construction managed to solve the "limited" problem. Firstly, based on inheriting original audio-visual education, it gives full play to the technological advantage of network to solve the problem of limited technological background; secondly, it solves the problems of limited influence scope and propagation distance by the sharing technique of network. The internet technology can solve the defect of limited subjects of high-quality courses effectively and present the superior resources of different regions on the internet, thus realize the resource sharing between learners and schools under a certain condition. However, there are also some defects in the teaching platform under the network environment. The most important defect is that the assessment standard and evaluation method of HighQuality Course Construction can't be realized. In addition, learners may be influenced by the course developer, so this mode is of no selectivity and initiative. In the society, the learning content and learning level assessment and identification can't be accepted widely. All these need new technological means to handle.

C. Development of High-Quality Courses under the Environment of MOOC
In the early years of the 21st century, with the deeper development of network education platform, internet teaching platform, represented by Coursera [11], Udacity [12] and edX [13], developed MOOC course rapidly. MOOC plays an important role in network teaching platform gradually. This is mainly determined by the technological background and operation characteristics of MOOC. Under the MOOC environment, High-Quality Course Construction is injected into new vitality. Firstly, MOOCS is famous for being "small", which divides the large subject content of traditional HighQuality Course Construction into many small modules, trying to realize learners' independent selection and initiative of their needs. This has been realized on the MOOC platform in the world. Secondly, the learning assessment and identification of MOOC have been accepted by most schools in west developed countries and are treated as students' learning evaluation method of relevant subjects. In China, Peking University has released its own MOOC, and course alliance of universities in Shanghai is also tending to MOOC. However, MOOC still has some defects in China. On the one hand, the assessment standard and method of High-Quality Course Construction also can't be realized; on the other hand, it can only realize tuition rather than propaganda, and learner can only be equipped with preliminary solving ability. All these problems should be solved with new technological background and government's coordination.

TABLE I Comparative of High-Quality Courses under Different Technological Backgrounds

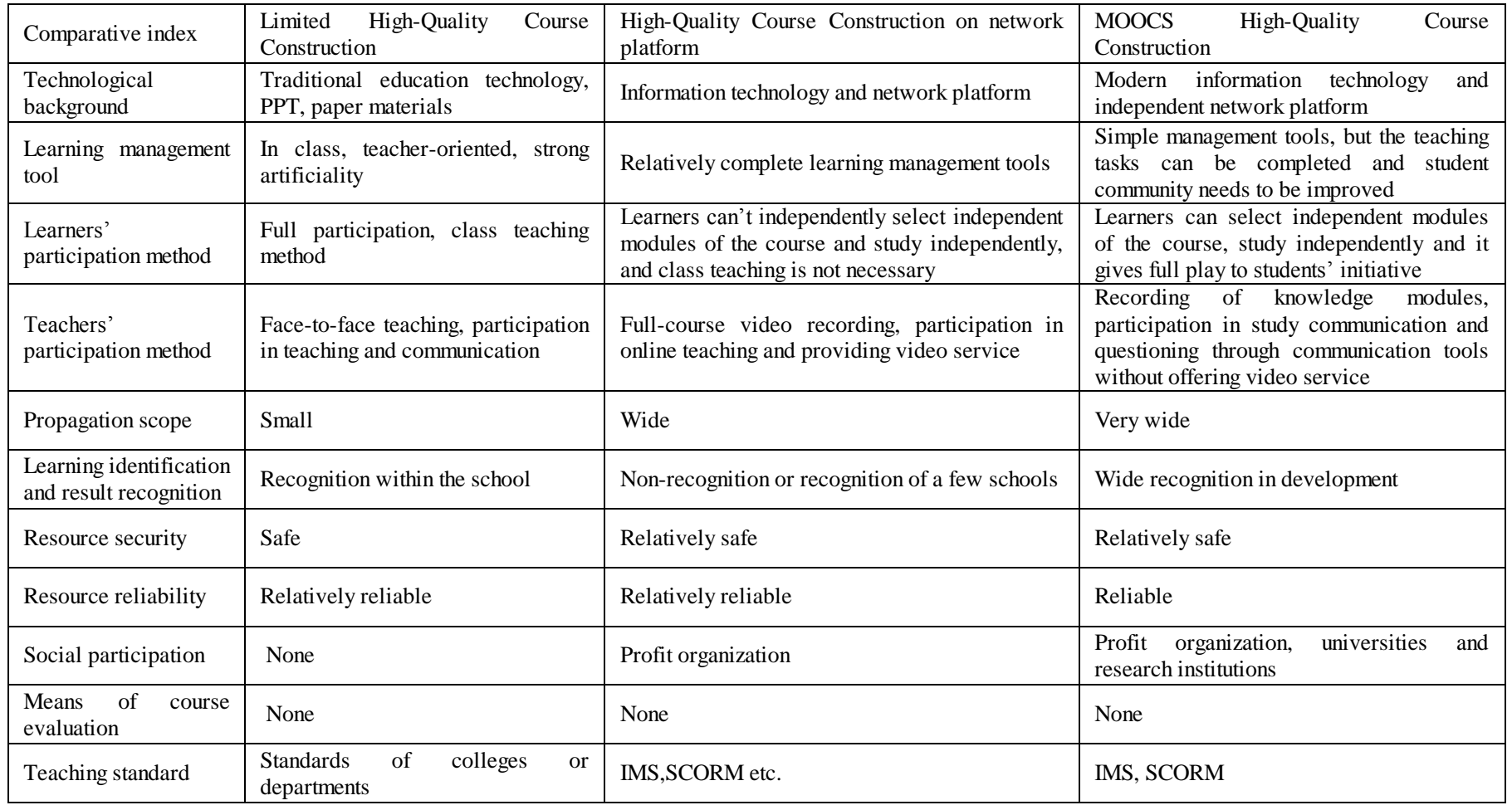




\section{Comparison of High-Quality Course Construction in Universities under the Support of the Idea of Sustainable Development}

According to the index of Edutools [14], the paper adopts different assessment indexes to have a detailed comparative analysis of threes kinds of High-Quality Course Construction, shown in TABLE 1. TABLE 1 indicates that the sustainable development of high-quality courses reflects the rich outcome of high-quality courses under the high-tech background and reveals that high-tech means has accelerated the rapid development of post high-quality courses. What's more, it shows the huge potential research and commercial opportunities, so is has become a hot research topic at the current stage. This study involves both teaching theory research and technical research. In the meantime, it is noticeable that under the guidance of sustainable development, High-Quality Course Construction with different technological backgrounds has achieved considerable development, and at the same time, it also brings about some defects, such as problems of independent selectivity recognition degree and reliability.

\section{Advantages, Problems and Countermeasures of High- Quality Course Construction under MOOC Environment}

Throughout the development history of high-quality courses, MOOC brings opportunities and challenges to HighQuality Course Construction, and the idea of sustainable development has injected vitality to the development of HighQuality Course Construction. MOOC provides a technical platform for the construction and propagation of high-quality courses, promotes the development of high-quality platform on a global scale, and attracts a batch of excellent higher education institutions to participate in it. By 2013, Coursera institution had established partnership with many famous universities including Stanford University, Princeton University, University of Pennsylvania, Hong Kong University and Shanghai Jiaotong University, and opened more than 500 online courses, which fully reveals MOOC resource construction has the following characteristics. Firstly, rapid development tendency driven by high-tech background. Relevant courses have grown from several subjects several years ago to hundreds today. Secondly, relevant guarantee of credit and quality of high-quality courses. By working with world's well-known universities and teaching institutions, the quality requirements of high-quality courses are guaranteed in China. Thirdly, internationalization of resources realized by technical means. MOOC, represented by the Internet, carries forward the advantage of the Internet's resource sharing and propagation, which can effectively realize the internationalization of superior educational resources. Fourthly, based on inheriting the complete subjects of traditional High-Quality Course Construction, it is further developed and expanded, solving the regional restriction and disciplinary limitation in High-Quality Course Construction, and realizing its internationalized development tendency towards complete subjects. All these characteristics of MOOC provide technical background and illustrations for HighQuality Course Construction in the universities of China.

\section{A. Enlightenment of MOOC on High-Quality Course Construction Reform}

(1)Learner-centered course design method. Through a rational analysis of the national high-quality courses at the present stage, it can be found that most resources adopt teacher-centered courses and resource realization as methodology and basically neglect learners' design method, without taking learners' technical background and learning needs into consideration. They just release the knowledge of a whole profession online, letting learners with certain knowledge background aimlessly carry on selective learning. What's worse, they also don't provide learners with an interactive working and learning environment.

(2) The construction mode of minimized knowledge module. At the present stage, Chinese high-quality courses are all divided according to different disciplines, the course design basically adopts a unified mode, which records recursively according to course chapters without considering learners' technical background, but instead, it treats every learner as a student. This violates learners' diversification and selectivity of learning content. In contrast, MOOC adopts the development strategy of small module and high-quality design and lays particular emphasis on the exquisite research and analysis of knowledge points instead of an overall display of the whole subject, which helps learners have learning selection at minimum cost according to their needs. Therefore, MOOC respects learners' independent selectivity and gives play to their learning initiative.

(3) Simple and open communication and discussion platform is in favor of learners' further study and wide discussion as well as improving their learning efficiency. MOOC platform offers peer review of homework, discussion board and document communication area, which is convenient for learners' study and communication. Besides, through the whiteboard, E-mail and BBS provided by a third party, it can realize learners' mutual communication and exchange. With the development of MOOC, an increasing number of MOOC operators provide more interactive learning methods and applications to facilitate students' learning and exchange and improve their learning efficiency.

\section{B. Defects and Countermeasures of High-Quality Courses under the Environment of MOOC}

Currently, MOOC has played an important driving role in the development of high-quality courses and it is of significant influence on Chinese High-Quality Course Construction. However, under the environment of MOOC, there are still some defects in High-Quality Course Construction, which are mainly reflected in the following aspects.

(1) MOOC can't realize the educational aim of preaching, teaching and dispelling doubts. MOOC relies on the network, so it can only propagate knowledge but can't realize emotional 
education, which can't be solved in the High-Quality Course Construction under the technical background. However, with the development of science and technology, particularly the development of network robots, this can be solved sooner or later. This is also an important bruising in High-Quality Course Construction.

MOOC lacks a unified evaluation system of high-quality courses, and it just relies on elite school effect to maintain the brand and quality of high-quality courses.

(2) MOOC lacks a unified uniformity of learning, evaluation and authentication of high-quality courses. Only several overseas universities admit the educational performance of MOOC, and there is basically no such authentication at home.

(3) Under the environment of MOOC, the transformation of learners and educators is an important restriction for the current development of MOOC. Under the network environment, how learners change their original learning habits and grasp online learning methods has become an important research topic. At the same time, the role transition of teachers is another restriction in the development of MOOC. Under the background of new technology, the workload of teacheroriented teaching is on the decrease, and afterwards, the workload of teacher-oriented dispelling doubts is on the increase. Thus, teachers should learn the successful experience from MOOC, have a crossed attempt on MOOC with the traditional course teaching carried out overseas, and offer assessment moderately.

MOOC is an educational communication means and it plays an important role in High-Quality Course Construction. Meanwhile, the defects of High-Quality Course Construction under the environment of MOOC can also be solved with the development of science and technology as well as further refinement of social division of labor. According to the detailed analysis above on High-Quality Course Construction under the environment of MOOC, here the authors put forward some suggestions on High-Quality Course Construction and evaluation system under the environment of MOOC.

(1) The differentiation of the teaching profession. Such refinement of social division of labor makes the teachers' occupational division more explicit under the environment of MOOC. It is suggested that under such environment, teachers should have a double occupational division. One hand, some of them should learn to preach and be skillful in dispelling doubts. This type of teachers mainly completes education and teaching activities through MOOC platform. The other type of expert teachers, apart from dispelling doubts, should also be good at preaching and teaching, passing on their accomplishment in the form of MOOC high-quality courses and benefiting more people.

(2) The assessment standard of high-quality courses under the MOOC platform are mainly manifested in the difference of educational methods and purposes at home and abroad. This requires Chinese educational management institutions to formulate evaluation method of high-quality courses under the environment of MOOC strictly control the operating access system of MOOC and truly develop the HighQuality Course Construction under the environment of MOOC.

(3) The recognition of learning evaluation system of High-Quality Course Construction under the environment of MOOC is also a problem to be solved currently. According to Chinese current conditions and the development history of higher education, generally, only the exams organized by administrative department for education can be recognized. Aiming at this situation, a two-step method can be adopted. First step is introducing MOOC to solve the problem of unfair educational resources at present. And then, after completing relevant courses, a unified evaluation within the school can be held, or under the circumstance of guaranteeing the quality of MOOC high-quality courses, network authentication can be adopted to complete the study.

\section{Further Reflection on Traditional High-Quality Course Construction under the Environment of MOOC}

Above discusses the opportunities, challenges and countermeasures existing in high-quality courses under the high-tech background of MOOC, whose development track can be summarized in Fig.1.

FIGURE 1 shows the important development stages of high-quality courses, from limited High-Quality Course Construction under traditional educational environment to High-Quality Course Construction under internet environment, then to High-Quality Course Construction under the environment of MOOC. And finally it also predicts the development of High-Quality Course Construction in the future. From the perspective of sustainable development, it truly reflects the development process of High-Quality Course Construction, and also reveals the high-teach support for every development of High-Quality Course Construction. Thus, it illustrates that high-tech background can inject vitality to highquality courses and it is an effective method to solve the problems existing in original High-Quality Course Construction. But it is certain that new defects are brought about, but these defects can be improved through new technology or solved by detailed social division of labor. 


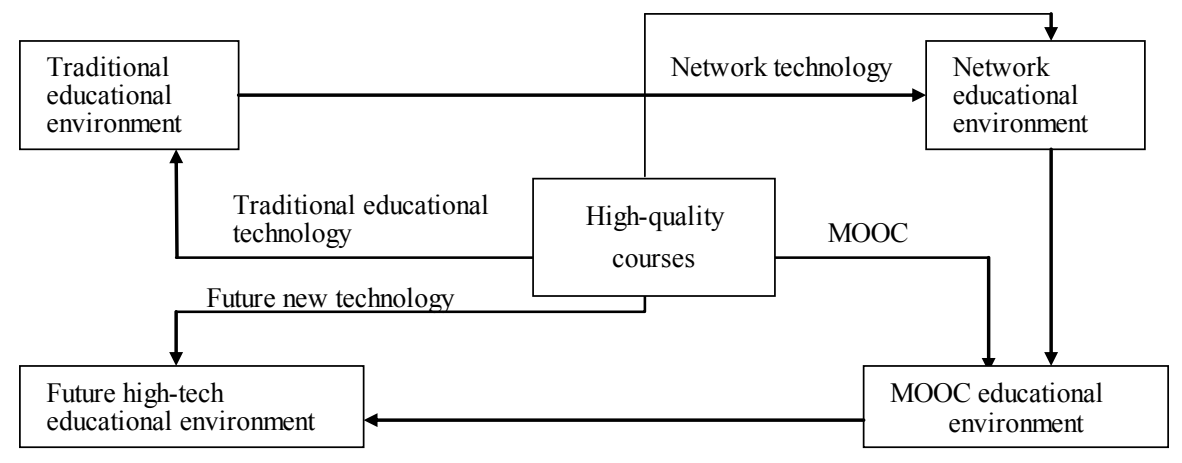

Fig. 1 Relationship between high-quality courses and educational technology

\section{Conclusions}

Based on analysis of the philosophical basis, current status and development progress of high-quality courses and MOOC in universities, the paper puts forward the direction of HighQuality Course Construction under the idea of sustainable development. It particularly demonstrates the advantages, defects, solutions and future development directions of highquality courses in the environment of MOOC in the future. The results will be significant to improve the superior educational resource sharing and handle the educational unfairness theoretically and practically.

\section{References}

[1] China education and research network center www.edu.cn/html/info/2013/mooc/index.shtml, 2013

[2] J. L. Jiao, "MOOC: opportunities and challenges," China Education Network, no. 4, pp. 21-23, April 2013.

[3] S. Y. Lao, X. P. Jiang, M. R. Lao, "The anlaysis of how MOOC in late IT era influenced higher education," Journal of Higher Education Research, vol.36, no.3, pp. 6-8, March 2013.

[4] J. B. Liu, X. Y. Zhao, J. J. Huang, et al., "Enlightenments brought out by MOOC to the teaching reform of Chinese university courses,"Journal of Higher Education Research, vol. 37, no. 4, pp. 21-27, April 2014.
[5] P. Wang, "The latest development and application of massive open online course: from cMOOC to xMOOC," Modern Distance Education, no.3, pp. 13-19, March 2013.

[6] D. Hao, "Reference analysis of MOOC in China," China Distance Education, no. 11, pp. 42-50, November 2013.

[7] L. Yuan, P. Stephen, H. L. Ma, "Analysis of Massive Open Online Courses initiatives," Open Education Research, vol.19, no.3, pp.56-62, 84, March 2013.

[8] A. Koutropoulos, R. J. Hogue, "How to succeed in a Massive Online Open Course(MOOC),"

www.learningsolutionsmag.com/articles/1023/how-to-succeedin-amassive-online-open-course-mooc, 2012

[9] L. Q Liu. "On the character of quality curriculum," Journal of Higher Education, vol.30, no.3, pp. 82-86, March 2009.

[10] S. F. Wang, "The main problems with the construction of quality course websites and their solutions," Higher Education Management, vol. 5, no.4, pp.57-62, April 2011.

[11] Coursera, "Take the world's best course, online for free," www.coursera.org, August 2014

[12] Uadcity, "Learn think do higher education for free," www.udacity.com, December 2013.

[13] Edx, "The future of online education for anyone, anywhere, anytime," www.edx.org, October 2014

[14] EduTools, www.edutools.info, October 2014. 